\title{
New Frontiers in Transplantation and Stem Cell Technology: A Brief Synopsis
}

\author{
Saba Javadi*, Joseph T. Brooks*, Gian-Angelo Obi-Umahi, Obi Ekwenna" \\ College of Medicine, University of Toledo, Toledo, OH, USA \\ Email: "Obi.ekwenna@utoledo.edu
}

How to cite this paper: Javadi, S., Brooks, J.T., Obi-Umahi, G.-A. and Ekwenna, O. (2018) New Frontiers in Transplantation and Stem Cell Technology: A Brief Synopsis. Open Journal of Organ Transplant Surgery, 8, 13-20.

https://doi.org/10.4236/ojots.2018.82002

Received: January 8, 2018

Accepted: May 12, 2018

Published: May 15, 2018

Copyright $\odot 2018$ by authors and Scientific Research Publishing Inc. This work is licensed under the Creative Commons Attribution International License (CC BY 4.0).

http://creativecommons.org/licenses/by/4.0/

\begin{abstract}
Since the first kidney transplant was performed in 1954 immense progress has been made in the world of transplantation. Modern immunosuppressive regimens have led to increasing graft and patient survival after solid organ transplantation. Furthermore, these advances have opened the door to new fields of transplantation such as composite tissue allotransplantation. These developments have made possible numerous types of transplantation including, but not limited to face, penile, and uterine transplantation. Moreover, innovations in genetic engineering and stem cell technology have contributed to rapid developments in the fields of xenotransplantation and the engineering of functional organs from induced pluripotent stem cells. As the prevalence of chronic diseases rises, so too will the necessity for organ transplantation. Thus, the transplant innovations of the modern era need to be expanded upon so as to continue to discover new ways to address organ shortages and the complications of transplantation.
\end{abstract}

\section{Keywords}

Transplantation, Stem Cell, Advances in Organ Transplantation

\section{Introduction}

On December 23, 1954, Dr. Joseph Murray performed the first successful human kidney transplant. Through the use of a patient's identical twin, he overcame the problem of rejection and ushered in a new era of enthusiasm for transplantation [1]. Subsequently, it was discovered that fraternal twin transplants could be made successful through the use of radiation to weaken the immune system [2]. During the 1960s, the work of Roy Calne and others indicated that immunosuppression could be achieved chemically using compounds like 6-mercaptopurine *These authors contributed equally to this work. 
and azathioprine [3]. Despite these advances, patient survival was quite low with most patients living only 3 - 6 months after transplantation [4]. However, in 1963, Tom Starzl showed that, by using a combination of azathioprine and prednisone, 1-year patient survival rates could exceed 70\% [5]. Starzl's immunosuppressive protocol became a standard for almost 20 years after, paving the way for new advances in transplantation. Starzl again altered the course of transplantation in the 1980s by pioneering the use of cyclosporine combined with prednisone [6]. Not only did this combination improve outcomes in kidney transplantation, but also it led to new successes in the transplantation of other organs in the years to come.

In the modern era, continued advancements in immunosuppressive drugs further the progress made in decades past. The use of mono- and poly-clonal antibodies such as antithymocyte globulin, basiliximab, and alemtuzumab has led to improvements in transplantation outcomes [7]. Other immunosuppressants such as sirolimus have followed suit. Immunosuppression has become more sophisticated and quite effective, the early years of hyperacute rejection has been eliminated, and long term maintenance immunosuppression is well tolerated. These developments have paved the way for new frontiers in transplantation, as the evolution of the history of transplantation continues relentlessly (Figure 1) [8].

One such development is composite tissue allotransplantation (CTA) which allows a graft consisting of heterogeneous antigenic tissues to be transplanted amongst a genetic mismatch [9]. As opposed to solid organ transplantation which typically consists of a more homogenous structure. The first attempt at CTA occurred in 1964 when an Ecuadorian team performed a hand transplant. Unfortunately, the transplant rejected after less than a month. However, since that time continuous advancements have been made [10]. In the late 1990s, the first successful hand transplants were performed in France and the United States [11]. Knee, femur, abdominal wall, and face transplants have since followed. Now, CTA has made possible a variety of transplant procedures including, but not limited to face, penis, uterus and hand.

CTA has opened new doors in the field of transplantation. Technical advancements and developments in immunosuppressive regimens have increased the feasibility for long-term success. The objective of this review is to provide insight into this progression along with outlining other innovations in transplantation such as stem cell technology and xenotransplantation. This report is novel given that it provides a historical perspective on the advancements that have

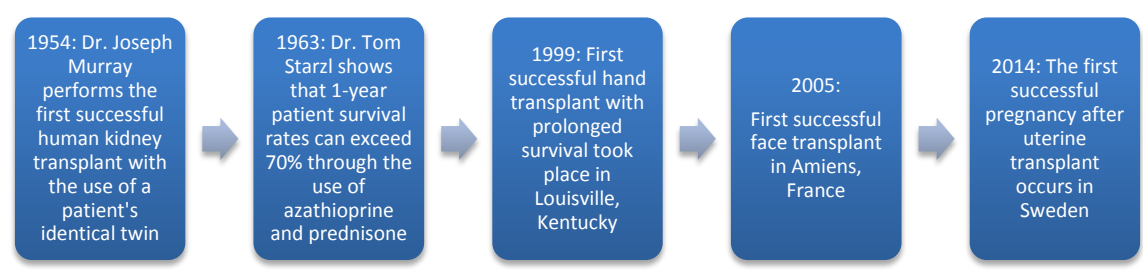

Figure 1. Landmark advances in transplantation. 
shaped the current status of transplantation and CTA while also providing insight on the possible future directions of the field.

\section{Face Transplantation}

Since the first successful face transplant (FT) in November 2005 at Amiens, France, numerous clinical cases have demonstrated this procedure as a valuable reconstructive option. According to Siemionow, there are currently 36 patients worldwide who have received face transplants [12]. The variety of face transplant procedures caries widely from partial to total, and cases that include all components including skin, muscle, bone and functional parts of eyelids, lips, and noses versus those that are limited to soft tissue alone [13]. Outcomes have been satisfactory with $89 \%$ patient survival, sensory recovery after 3 to 8 months, and motor recovery after 6 to 18 months [14] [15]. Aesthetically, post-transplant outcomes are generally an improvement over pre-transplant. However, in many cases patients still have some irregularity. A major issue of facial transplantation, as with solid organ transplantation, is that patients need to remain under life-long immunosuppressive treatment putting them at risk of infections, metabolic complications, nephrotoxicity, hypertension and tumors [16]. Additionally, there can be psycho-social ramifications from face transplantation. However, most patients seem to regain self-confidence and have increased levels of happiness after transplantation [17] [18]. Finally, there are controversies about the cost of face transplantation. The estimated cost is between $\$ 250,000$ and $\$ 350,000$ not including the extensive cost of a lifelong immunosuppressive regimen [19]. Given these high costs, and the fact that many insurance companies do not cover the procedure, it is unclear if the benefits outweigh the costs. Overall, face transplantation has demonstrated its ability to offer functional, social and aesthetic rehabilitation for patients. However, there are many unresolved issues that make it an experimental procedure requiring a multidisciplinary approach from research and clinical teams. Further research into this topic is needed to improve outcomes and decreases costs.

\section{Penile Transplantation}

The first penile allotransplantation in the United States, which occurred in May 2016, was shown to restore external genital appearance, urinary function and sexual function. The genitourinary vascularized composite allotransplantation (GUVCA) occurred at Massachusetts General Hospital with a multidisciplinary team of plastic surgeons, urologists, radiologists, pathologists, psychiatrists, transplant coordinators, nurses, social workers, dietitians and financial coordinators [19]. The procedure began with allograft procurement concurrent with recipient preparation, including the dissection of the right groin and penile stump. After all critical nerves and vessels paralleling the allograft were exposed, revascularization began with anastomoses of the urethra, corpora, cavernosal and dorsal arteries [20]. Flow to these vessels and skin was established using a 
vein graft that did not require multiple arterial anastomoses, which was previously expected due to the estimation of the robust collateral circulation of the penis. The allograft had strong capillary refill, Doppler signals, and no anastomotic leaks, indicating successful perfusion. An acute rejection episode required the use of additional T-cell depletion therapy showing positive recovery. At about 7 months the patient reported sensation of penile shaft and spontaneous penile tumescence [21]. A drawback of this procedure is that maintenance immunosuppression will be lifelong, exposing the patient to potential systemic complications. By managing chronic rejection, GUVCA has shown to successfully restore anatomic appearance and genitourinary function after severe genitourinary tissue loss [22].

\section{Uterine Transplantation}

Uterine factor infertility affects approximately 1 in 500 women worldwide [20]. This specific type of infertility is outside the realm of successes seen in in vitro fertilization and intracytoplasmic sperm injection therapies. The field of uterine transplantation has developed as a result. According to Castellon et al., a total of 25 successful uterine transplants have been performed. The first live birth after uterine transplant occurred in 2014, and five more have followed since [21]. Uterine transplantation can involve either a living or deceased donor. While there are surgical risks and psychological consideration involved in living donor transplantation, the outcomes in solid organ transplantation are generally superior to those of deceased donors. The major concerns regarding uterine transplantation involve the viability of the graft for future pregnancy and the effects of immunosuppression on fertility and pregnancy outcomes [23]. Rejection episodes have occurred in the majority of pregnancies after uterine transplantation, however, these episodes were reversed with IV corticosteroids and the children were born healthy [24]. The use of an immunosuppressive regimen that is FDA-approved for use in pregnancy results in a risk of congenital abnormalities that is comparable to normal pregnancy. Overall, uterine transplantation has demonstrated the potential to be an effective treatment for uterine factor infertility. With the advent of newer immunosuppression regimens, the number and success rate of these procedures will likely increase.

\section{Xenotransplantation}

The demand for organ transplants overwhelmingly exceeds the supply. In the United States alone there are approximately 116,000 people waiting to receive an organ transplant [25]. Twenty of those people will die each day while waiting for a transplant [26]. Because of these statistics, xenotransplantation, or the transplantation of organs or cells from another species to humans, is an exciting clinical prospect. Pig-to-human xenotransplantation seems to hold the most promise for this field. However, there are significant immunological barriers involved. The most significant of these are human anti-pig antibodies that target galac- 
tose- $\alpha 1$, 3-galactose antigens expressed on porcine organs [27]. Porcine organs that are knockouts for the $\alpha 1$, 3-galactosyltransferase gene have shown promise in preventing early rejection, however, other antibodies and immune cells can still induce rejection [28]. Currently, xenotransplantation of islet or neuronal cells shows more promise than that of organ xenotransplantation. Pig islet cells have been shown to continue to function in non-human primates for more than a year [29] [30]. Success has also been demonstrated in xenotransplantation of dopamine-producing cells from pigs to monkeys with a Parkinson's-like condition [28] [29]. Furthermore, cardiac graft survival in pig-to-non-human primates has shown survival of up to 8 months [29] [30]. It is hoped that the use of novel gene editing technologies such as CRISPR-Cas9 will help overcome some of the remaining hurdles in xenotransplantation [31]. For now, further research is needed to allow progression of this promising field.

\section{Stem Cells and Regenerative Medicine}

The demand for transplantable organs, the ever present complications associated with allogeneic transplantation and the challenges of associated with antirejection therapy are the major pillars of modern bioengineering, regenerative medicine and transplant research. The cell types used in organ bioengineering and regenerative medicines, range from differentiated adult cells to undifferentiated progenitor cells and stem cells [32]. In 2006, Shinya Yamanaka's lab in Japan demonstrated that fully differentiated adult cells could be reprogrammed into pluripotent stem cells through the activation of four transcription factors: Oct3/4, Sox2, c-Myc, and Klf4 [33]. These cells were called human induced pluripotent stem cells (iPSCs). Yamanaka's findings paved the way for the field of regenerative medicine. Since that time, Takebe et al. succeeded in generating three dimensional, vascularized, and functional human liver buds from iPSCs in vitro. Subsequently, they successfully transplanted these liver buds into mice and demonstrated improved survival in mice with induced liver failure [34]. In March of 2017, Mandai et al. successfully transplanted retinal pigment epithelial cells which were differentiated from iPSCs into a patient with macular degeneration. One year after transplantation, there were no reported complications. Although the patient reported having better vision, objective testing revealed it had neither improved nor worsened [35]. The use of iPSCs for generation and subsequent transplantation of engineered human organs remains at an early stage. Though there has been tremendous success in the identification, isolation of stems cells, proliferation and expansion of these cells in vitro to clinically relevant scales remains a serious challenge. The history of transplant suggests that its goals and methodologies share a common path to success and envisioned by experts in regenerative medicine. The ability to bypass the need for immunosuppression, and generate limitless supply of transplantable organs is the appeal of regenerative medicine, which is intertwined with the future of modern clinical transplantation. 


\section{Conclusion}

Over half a century has passed since the first successful organ transplant. Since then, significant progress has been made in the field ranging from whole organ transplants (liver, kidney, heart, intestine, pancreas, uterus, lungs) CTA to iPSC tissue engineering. The notable success of organ transplantation for the treatment of end-organ diseases has resulted in overwhelming demand without a matching supply. Thus, transplantation has been the victim of its own success. The supply and demand discrepancies is projected to continue on an unfavorable path given the massive incidence of chronic noncommunicable diseases [36]. The modern era of transplant innovations will focus on organ engineering, and regeneration combined with expansion of immunologic tolerance, expansion of transplant indications, donor pool and types of transplants offered. Despite these remarkable successes, there remains a great need to address the obstacles to transplantation and the new frontiers; rejection, long-term survival, donor supply and costs. It is inevitable that for continued success in the "new frontiers in transplantation and stem cell technology", efforts should be made to eliminate immunological barriers, create immunologic tolerance, increase supply of organs and control the price tag of these advances.

\section{References}

[1] Murray, J.E., Merrill, J.P. and Harrison, J.H. (1955) Renal Homotransplantation in Identical Twins. Surgical Forum, 6, 432-436.

[2] Hamburger, J., Vaysse, J., Crosnier, J., Tubiana, M., Lalanne, C.M., Antoine, B., Auvert, J., Soulier, J.P., Dormont, J., Salmon, C., et al. (1959) Transplantation of a Kidney between Non-Monozygotic Twins after Irradiation of the Receiver: Good Function at the Fourth Month. Presse Medicale, 67, 1771-1775.

[3] Calne, R.Y. (1960) The Rejection of Renal Homografts: Inhibition in Dogs by 6-Mercaptopurine. Lancet, 1, 417-418. https://doi.org/10.1016/S0140-6736(60)90343-3

[4] Goodwin, W.E. and Martin, E.C. (1963) Transplantation of the Kidney. Urological Survey, 13, 229-248

[5] Starzl, T.E., Marchioro, T.L. and Waddell, W.R. (1963) The Reversal of Rejection in Human Renal Homografts with Subsequent Development of Homograft Tolerance. Surgery, Gynecology \& Obstetrics, 117, 385-395.

[6] Starzl, T.E., Weil III, R., Iwatsuki, S., Klintmalm, G., Schroter, G.P.J., Koep, L.J., Iwaki, Y., Terasaki, P.I. and Porter, K.A. (1980) The Use of Cyclosporin A and Prednisone in Cadaver Kidney Transplantation. Surgery, Gynecology \& Obstetrics, 151, 17-26.

[7] Mahmud, N., Klipa, D. and Ahsan, N. (2010) Antibody Immunosuppressive Therapy in Solid Organ Transplant: Part I. $m A b s, 2,148-156$. https://doi.org/10.4161/mabs.2.2.11159

[8] Salvatori, M., et al. (2015) Semi-Xenotransplantation: The Regenerative Medicine-Based Approach to Immunosuppression-Free Transplantation and to Meet the Organ Demand. Xenotransplantation, 22, 1-6. https://doi.org/10.1111/xen.12122

[9] Giuglea, C., Coman, C., Marinescu, S., Florescu, I. and Lascar, I. (2013) Transplantation of Composite Tissue Allograft: Scientific Bases and Clinical Applications. 
Journal of Medicine and Life, 6, 40-44.

[10] Ravindra, K.V., Wu, S., Bozulic, L., Xu, H., Breidenbach, W.C. and Illdstad, S.T. (2008) Composite Tissue Transplantation: A Rapidly Advancing Field. Transplantation Proceedings, 40, 1237-1248. https://doi.org/10.1016/j.transproceed.2008.04.003

[11] Dubernard, J.M., Owen, E., Herzberg, G., et al. (1999) Human Hand Allograft: Report on First 6 Months. The Lancet, 353, 1315-1320. https://doi.org/10.1016/S0140-6736(99)02062-0

[12] Siemionow, M. (2016) The Miracle of Face Transplantation after 10 Years. British Medical Bulletin, 120, 5-14. https://doi.org/10.1093/bmb/ldw045

[13] Siemionow, M. and Ozturk, C. (2012) Face Transplantation: Outcomes, Concerns, Controversies, and Future Directions. Journal of Craniofacial Surgery, 23, 254-259. https://doi.org/10.1097/SCS.0b013e318241b920

[14] Stokes, M. (2016) A Decade of Face Transplantation: Lessons Learned and What Lies Ahead. Plastic Surgery News, 24-25.

[15] Siemionow, M., Papy, F., Alam, D., et al. (2009) Near-Total Human Face Transplantation for a Severely Disfigured Patient in the USA. The Lancet, 374, 203-209. https://doi.org/10.1016/S0140-6736(09)61155-7

[16] Infante-Cossio, P., Barrera-Pulido, F., Gomez-Cia, T., Sicilia-Castro, D., Garcia-Perla-Garcia, A., Gacto-Sanchez, P., et al. (2016) Facial Transplantation: A Concise Update. Medicina Oral, Patologia Oral Y Cirugia Bucal, 18, 263-271.

[17] Paradis, C., Siemionow, M., Papay, F., et al. (2010) Ethical Considerations in the First American Face Transplant. Plastic and Reconstructive Surgery, 126, 896-901. https://doi.org/10.1097/PRS.0b013e3181e3b63d

[18] Coffman, K.L. and Siemionow, M.Z. (2014) Ethics of Facial Transplantation Revisited. Current Opinion in Organ Transplantation, 19, 181-187. https://doi.org/10.1097/MOT.0000000000000058

[19] Siemionow, M., Gatherwright, J., Djohan, R., et al. (2011) Cost Analysis of Conventional Facial Reconstruction Procedures Followed by Face Transplantation. American Journal of Transplantation, 11, 379-385. https://doi.org/10.1111/j.1600-6143.2010.03373.x

[20] Cetrulo, C.L., Li, K., Salinas, H.M., Treiser, M.D., Schol, I., Barrisford, G.W. and Ko, D.S.C. (2017) Penis Transplantation: First US Experience. Annals of Surgery, 267, 983-988. https://doi.org/10.1097/SLA.0000000000002241

[21] Johannesson, L. and Jarvholm, S. (2016) Uterus Transplantation: Current Progress and Future Prospects. International Journal of Women's Health, 8, 43-51. https://doi.org/10.2147/IJWH.S75635

[22] Castellón, L.A.R., Amador, M.I.G., Gonzalez, R.E.D., Eduardo, M.S.J., Diaz-Garcia, C., Kvarnstrom, N. and Branstrom, M. (2017) The History behind Successful Uterine Transplantation in Humans. JBRA Assisted Reproduction, 21, 126-134. https://doi.org/10.5935/1518-0557.20170028

[23] http://optn.transplant.hrsa.gov

[24] Cooper, D.K.C., Ezzelarab, M.B., Hara, H., et al. (2016) The Pathobiology of Pig-to-Primate Xenotransplantation: A Historical Review. Xenotransplantation, 23, 83-105. https://doi.org/10.1111/xen.12219

[25] Hering, B.J., Wijkstrom, M., Graham, M.L., et al. (2006) Prolonged Diabetes Reversal after Intraportal Xenotransplantation of Wild-Type Porcine Islets in Immunosuppressed Nonhuman Primates. Nature Medicine, 12, 301-303.

https://doi.org/10.1038/nm1369 
[26] Cardona, K., Korbutt, G.S., Milas, Z., et al. (2006) Long-Term Survival of Neonatal Porcine Islets in Nonhuman Primates by Targeting Costimulation Pathways. Nature Medicine, 12, 304-306. https://doi.org/10.1038/nm1375

[27] Martin, C., Plat, M., Nerriére-Daguin, V., et al. (2005) Transgenic Expression of CTLA4-Ig by Fetal Pig Neurons for Xenotransplantation. Transgenic Research, 14, 373-384. https://doi.org/10.1007/s11248-004-7268-4

[28] Badin, R.A., Padoan, A., Vadori, M., et al. (2010) Longterm Clinical Recovery in Parkinsonian Monkey Recipients of CTLA4-Ig Transgenic Porcine Neural Precursors. Transplantation, 90, 47. https://doi.org/10.1097/00007890-201007272-00090

[29] Kuwaki, K., Tseng, Y.L., Dor, F.J., et al. (2005) Heart Transplantation in Baboons using Alpha1, 3-Galactosyltransferase Gene-Knockout Pigs as Donors: Initial Experience. Nature Medicine, 11, 29-31. https://doi.org/10.1038/nm1171

[30] Tseng, Y.L., Kuwaki, K., Dor, F.J., et al. (2005) a 1,3-Galactosyltransferase Gene-Knockout Pig Heart Transplantation in Baboons with Survival Approaching 6 Months. Transplantation, 80, 1493-1500. https://doi.org/10.1097/01.tp.0000181397.41143.fa

[31] Ekser, B., Li, P. and Cooper, D.K.C. (2017) Xenotransplantation: Past, Present, and Future. Current Opinion in Organ Transplantation, 22, 513-521. https://doi.org/10.1097/MOT.0000000000000463

[32] Koh, C.J. and Atala, A. (2004) Tissue Engineering, Stem Cells, and Cloning: Opportunities for Regenerative Medicine. Journal of the American Society of Nephrology, 15, 1113-1125. https://doi.org/10.1097/01.ASN.0000119683.59068.F0

[33] Takahashi, K. and Yamanaka, S. (2006) Induction of Pluripotent Stem Cells from Mouse Embryonic and Adult Fibroblast Cultures by Defined Factors. Cell, 126, 663-676. https://doi.org/10.1016/j.cell.2006.07.024

[34] Takebe, T., Sekine, K. and Enomura, M. (2013) Vascularized and Functional Human Liver from an iPSC-Derived Organ Bud Transplant. Nature, 499, 481-485. https://doi.org/10.1038/nature12271

[35] Mandai, M., Watanabe, A., Kurimoto, Y., et al. (2017) Autologous Induced Stem-Cell-Derived Retinal Cells for Macular Degeneration. NEJM, 376, 1038-1046. https://doi.org/10.1056/NEJMoa1608368

[36] Collaborators, G.B.D.R.F. (2016) Global, Regional, and National Comparative Risk Assessment of 79 Behavioural, Environmental and Occupational, and Metabolic Risks or Clusters of Risks, 1990-2015: A Systematic Analysis for the Global Burden of Disease Study 2015. The Lancet, 388, 1659-1724. https://doi.org/10.1016/S0140-6736(16)31679-8 